ISSN 0103-5150

Fisioter. Mov., Curitiba, v. 29, n. 3, p. 569-579, Jul./Set. 2016

Licenciado sob uma Licença Creative Commons

DOI: http://dx.doi.org.10.1590/1980-5918.029.003.A015

(c)

\title{
Carpal tunnel syndrome: mobilization and segmental stabilization
}

\author{
Mobilização neural e estabilização segmentar \\ na síndrome do túnel do carpo
}

\author{
David Fedrigo Moraes ${ }^{[a]}$, Andréa Licre Pessina Gasparini ${ }^{[b]}$, \\ Marco Aurélio Sertório Grecco ${ }^{[c]}$, Nathalia Helen Neves Almeida ${ }^{[a]}$, Tamiris Cassin Mainardi ${ }^{[a]}$, \\ Luciane Fernanda Rodrigues Martinho Fernandes ${ }^{[\mathrm{b}]^{*}}$ \\ [a] Universidade Federal do Triângulo Mineiro (UFTM), Uberaba, MG, Brazil \\ [b] Universidade Federal do Triângulo Mineiro/ Departamento de Fisioterapia Aplicada (UFTM), Uberaba, MG, Brazil \\ [c] Universidade Federal do Triângulo Mineiro/ Departamento de Cirurgia (UFTM), Uberaba, MG, Brazil
}

\begin{abstract}
Introduction: Carpal tunnel syndrome is a compressive neuropathy, frequently seen in women. Conservative treatment for carpal tunnel syndrome focuses on control of symptoms and the nervous path, due to the possibility of double compression. Objective: To assess whether a protocol with emphasis on motor control techniques, including segmental cervical stabilization and neural mobilization, has better results in mechanical reorganization and reduction of symptoms when compared with classic therapeutic exercise techniques in the conservative treatment of carpal tunnel syndrome. Methods: This pilot study was a randomized, double-blind clinical trial, involving 11 women with an average age of $54( \pm 6)$ years, allocated to either a classical
\end{abstract}

\footnotetext{
*DFM: BS, e-mail: david.fisiouftm@gmail.com ALPG: PhD, e-mail: deiapgasparini@ig.com.br MASG: Doctoral Student, e-mail: marcoasgrecco@metalnet.com.br NHNA: BS, e-mail: nathalianalmeida@hotmail.com TCM: BS, e-mail: tamiris_mainardi@hotmail.com LFRMF: PhD, e-mail: fernandes.luciane72@gmail.com
} 
kinesiotherapy group (CG) or experimental group (EG). The intervention spanned 12 weeks, with assessments prior to and following therapy, using the monofilament test, handgrip dynamometer, and BCTQ DASH, and PRWE questionnaires. All normally distributed data was analysed with Student's T-tests. Results: Both groups exhibited an increase in grip strength and relief of symptoms with improved functionality. There was a significant reduction in sensitivity noted in the CG group, and a significant increase in grip strength observed in the EG group. Conclusion: The experimental protocol group exhibited better results in mechanical reorganization, reflected in increased strength, sensitivity, and improved functionality, when compared to the group with conventional therapeutic exercise, but without the same symptomatic reduction.

Keywords: Carpal Tunnel Syndrome. Nerve Crush. Rehabilitation.

\section{Resumo}

Introdução: Compreende a Síndrome do Túnel do Carpo (STC) uma neuropatia compressiva frequente em mulheres. No tratamento conservador, a ênfase é dada ao controle da sintomatologia e ao trajeto nervoso devido à hipótese de dupla compressão. Objetivo: Avaliar se um protocolo com ênfase nas técnicas de controle motor, constituído por estabilização segmentar cervical e mobilização neural, apresentam melhores resultados na reorganização mecânica e redução dos sintomas quando comparado com técnicas de cinesioterapia clássica. Métodos: Estudo piloto de um ensaio clínico randomizado duplo cego, em 11 mulheres, alocadas em Grupo Cinesioterapia clássica (GC), e Grupo Experimental (GE). A intervenção foi de 12 semanas, com avaliações no pré e pós, por meio da estesiometria, dinamometria de preensão palmar e aplicação dos questionários BCTQ, DASH e PRWE. Resultados: Ambos aumentaram a força de pinça com alívio da sintomatologia e melhora da funcionalidade. Houve diminuição da sensibilidade no GC e aumento significativo da força de preensão palmar no GE. Conclusão: O grupo do protocolo proposto apresentou melhores resultados na reorganização mecânica, com reflexo no aumento da força, da sensibilidade e melhora da funcionalidade, quando confrontado ao grupo com cinesioterapia convencional, porém sem o mesmo impacto para a redução dos sintomas.

Palavras-chave: Síndrome do Túnel Carpal. Compressão Nervosa. Reabilitação.

\section{Introduction}

Carpal tunnel syndrome (CTS) is a neuropathy commonly observed in women, whereby the median nerve suffers compression when passing through the carpal tunnel in the wrist (1). CTS accounts for approximately $90 \%$ of all compressive peripheral neuropathies, and will affect 10 to $15 \%$ of the population at some point within their lifetime. Incidence of CTS has quadrupled over the past decade, occurring in approximately 3.4 new cases per thousand inhabitants, per year (2). Individuals suffering from this disorder have both nocturnal and daytime symptoms, manifesting as pain and numbness in the territory of the median nerve; including burning pain, numbness and sharp sensations related to oedema. With the evolution of compressive frame, the individual may suffer from mechanical disruption with severe sensory loss in the hands and atrophy of the thenar eminence, accentuating the reduction of hand strength, both of which can manifest as functional limitations $(2,3)$.
Conservative treatment for CTS emphasises control of symptoms with use of orthotics to preserve the carpal tunnel volume (4) and nervous path, a product of the hypothesis established by Upton and McComas (5), which suggests that axons that are suffering in a region are more likely to also suffer in another region. The hypothesis of double nerve compression speculates that the nerve undergoes an additional compression, beyond that caused by the carpal tunnel, in the cervical root, by disruption of bone architecture and biomechanics between the superficial and deep musculature of the region $(6,7)$. As a product of this, a need exists to establish a physical therapy protocol aimed at not only conventional CTS, but also the nerve root.

Motor control techniques and automation of reorganization (8) appears as allied to the increment of physical therapy in CTS. Segmental stabilization, through deep isometric muscle contraction, in synchronous with body weight support, aims to provide support to the spine and control segment, and to 
promote functional stability of the region (9). Neural mobilization is a neurodynamic technique aimed at restoring the physiological function of the nerve, promoting increased capillary blood flow and oxygen supply, which results in improved density of the axoplasmic flow and, consequently, nerve conduction $(10,11)$.

Therefore, the aim of this study was to identify a protocol that emphasises motor control techniques, consisting of segmental stabilization, cervical and neural mobilization. Further, we sought to identify whether this protocol would result in better mechanical reorganization and reduction of symptoms, when compared with classic therapeutic exercise techniques in the treatment of conservative CTS.

\section{Methods}

\section{Study and sample characterisation}

This pilot study was a randomized, double-blind clinical trial conducted between January and June 2015, including 15 women diagnosed with carpal tunnel syndrome who were submitted to conservative treatment. These individuals were enrolled from the orthopaedic department of the Clinic of the Universidade Federal do Triângulo Mineiro (UFTM). After clinical diagnosis, as established by the treating physician, patients were informed about the objectives and procedures to be performed, and, following agreement, signed the informed consent (IC) form. This study was approved by the ethics committee of the UFTM, No. 923 826, and all participants voluntarily participated, as required by Resolution 466/12 of the National Health Council. Of the initial cohort, four were excluded due to abandonment of the medical and physical therapy, resulting in a final sample of 11 women.

\section{Procedures}

Evaluation

A single, trained examiner performed all evaluations. Patient data, including name, age, dominant hand, education and employment status, as well as any history of dysfunction (including date of onset of symptoms, unilateral or bilateral involvement) were recorded. Subsequently, subjects were evaluated for sensitivity, strength, symptoms, and function.
Sensitivity was assessed using SemmesWeinstein monofilaments (12), produced by SORRI ${ }^{\circledR}$. Five monofilaments, in combination with the three landmarks establishing the territory of the median nerve, were exploited as in the standardized evaluation protocol proposed by Rosén and Lundborg (13). This was done to assess only the perception of touch sensitivity. Response sensitivity is graded by colour (green, blue, purple, red, pink and black), with numerals between zero and five corresponding to given colours; five for green, four for blue, three for lilac, two for red, one for the pink and zero for black. Three locations, corresponding to the territory of the median nerve, were evaluated, with the final score ranging from 0 to 15 . Those with a greater score exhibited better sensitivity (13).

For evaluating outcomes of both palmar and pinch pulp-to-pulp strength, grip and pinch gauge dynamometers (E-Link Kit, Biometrics ${ }^{\circledR}$ ) were used. Individuals performed three maximal contractions, with a one-minute interval between contractions in order to avoid muscle fatigue. From this, a simple average was calculated (14). The handgrip dynamometer was adjusted to the second resistance position, as to be appropriate for the assessment of female subjects (15). Patients were positioned with the shoulder adducted, arm near the trunk, the elbow flexed at $90^{\circ}$, the forearm in a neutral position and the wrist in slight extension (16).

Assessment regarding the symptoms and function of the upper limbs was performed using three, self-administered questionnaires: The Boston Carpal Tunnel Questionnaire (BCTQ), the Disabilities of the Arm, Shoulder and Hand (DASH), and the Patient Rated Wrist Evaluation (PRWE).

The BCTQ is a specific instrument for CTS, and aims to assess the severity of symptoms (BCTQEGS) and functional status (BCT-EEF). The version used in this study was translated and validated by Campos et al. (17). Disabilities and functional limitations affecting the upper limb were evaluated in greater detail by the DASH questionnaire, using the first module as translated and validated by Orfale et al. (18). Further, the PRWE questionnaire, as translated and validated by Rodrigues (19), was used to assess patient pain levels (PRWE-Pain) and degree of dysfunction (PRWE-Dysfunction) based on a graduated scale between 0 and 10 (20). The scores for each questionnaire were graded following the protocols established by the corresponding literature. 


\section{Randomization and blinding}

Randomization was performed in the presence of all patients and the physiotherapy team, using fifteen envelopes distributed randomly on a table. Patients were directed to pick an envelope from the table in a random fashion, mark it with their name, and hand to a staff member, without opening. Inside each envelope, the assignment to either the classic kinesiotherapy group (CG) or experimental group (EG) was identified. Following the opening of envelopes, performed by a member responsible for allocation, the volunteers received information about the routine of intervention. Patients were unaware of the differences in treatment between the groups. To ensure double-blinding, the examiner was unaware of the composition of the groups before making final evaluations.

\section{Intervention}

Patients performed the treatment program for 12 weeks, at a frequency of twice a week and duration of 60 minutes per session. All treatment protocols were guided and accompanied by two previously trained staff members (called "instructors"). Treatment sessions for both groups were performed at the same time, and on the same days, but in different rooms.

All patients received a static splint neutrally positioned, suitable for night use and intermittent or full daytime use, as a means to ameliorate the occurrence of paraesthesia symptoms (21).

The CG received a classic therapeutic exercise program, consisting of stretching the active muscles in the neck and shoulder region, active exercises of the upper limbs with an exercise stick, stretching and strengthening of the flexor and extensors of the wrist and of the intrinsic hand muscles, and exercises to promote sensory reeducation, as recommended by Santos and Pereira (22).

In the EG, an exercise protocol was established (Figure 1, 2 and 3) based on motor control principles, as proposed in the model by Panjabi (23), characterised with a tripod attention to the muscular system, joint and peripheral nervous system. The focus was on segmental stabilization as a means of ensuring functional mechanics without stress isometric activation of the cervical deep muscles. Further to this, neural mobilization of the median nerve and neuro-axis was performed in order to regulate the axoplasmic flow and, therefore, the supply of blood and oxygen, thereby improving the nerve conduction
$(9,10)$. Additional exercises included: cervical myofascial release, relaxation and activation of the stabilizing muscles of the shoulder girdle, sensory reeducation techniques, tendon gliding of superficial and deep flexors of the fingers, isometric 6-second activations of the intrinsic muscles of the hand, and circular movements with a ball of foam under the motor territory of the median nerve to promote heating and increased blood flow.

A

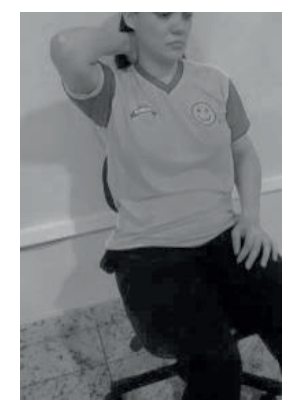

B.

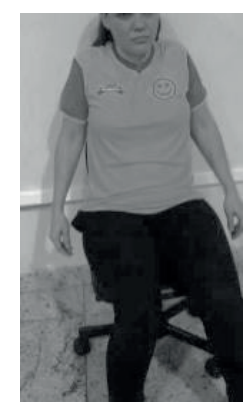

C.
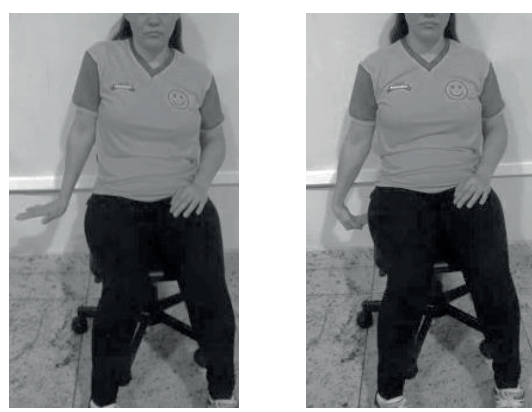

D.
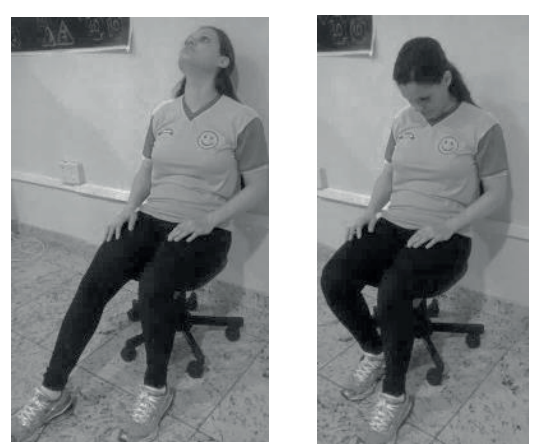

Figure 1 - (A) Cervical myofascial release, (B) Scapular mobilization, (C) Neural mobilization - median (D) Neural mobilization - neuraxial. 
A.

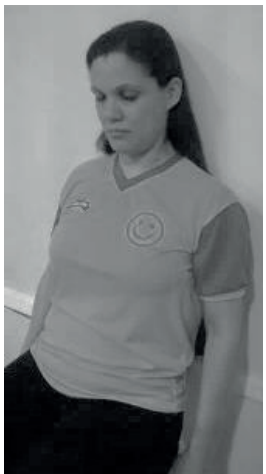

B.
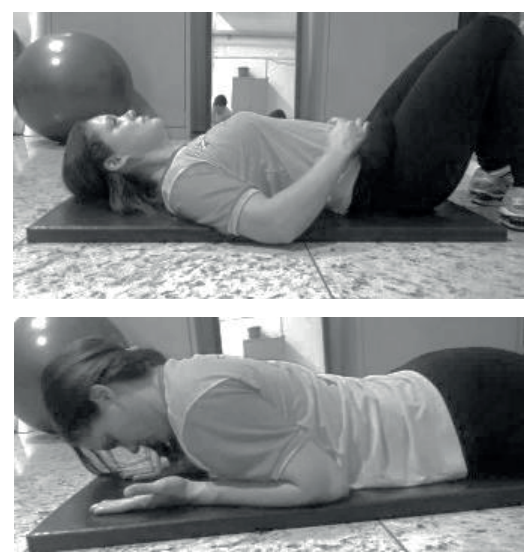

C.

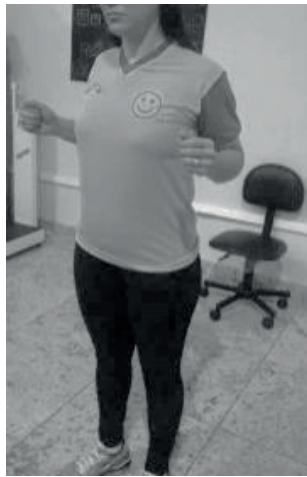

D.

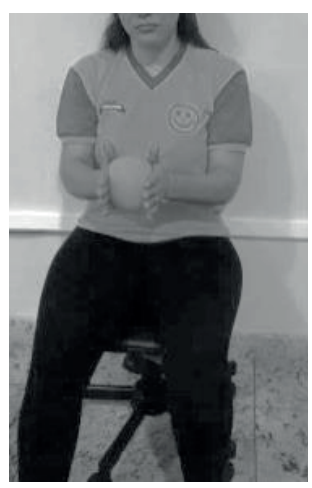

Figure 2 - (A / B) Segmental Stabilization (C) Rhomboid and trapezium muscle activation, (D) Activation of the intrinsic hand muscles.
A.

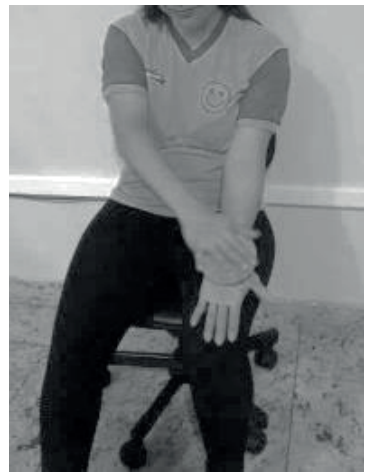

B.

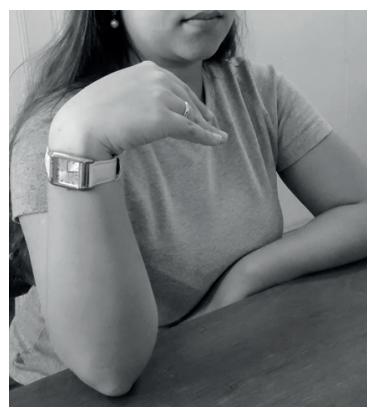

Figure 3 - (A) Massage of the motor territory of the median nerve, (B) Slip tendon.

Statistical analysis

To evaluate the results of mechanical reorganization, response variables were analysed: sensitivity, grip strength, pinch pulp-to-pulp force, and values from DASH and BCTQ-EEF questionnaires. To evaluate the reduction of symptoms, outcomes were drawn from the PRWE-Pain and BCTQ-EEG questionnaires. Explanatory variables included the assessment (first and last) and group (control and intervention). The women's characterization was done by the mean and standard deviation for age and relative frequency for the other qualitative variables (dominance, employment and educational activities). In analysis, only dominant hands were evaluated. Normality was investigated using the Shapiro-Wilk test and data evaluations were submitted to descriptive and inferential analysis with a $5 \%$ significance level.

In the intra-group analysis, to compare dependent samples (initial assessment $X$ final assessment of each group) we used Student's T-tests. For intergroup analysis, comparing the independent samples (CG XEG), the difference between values from the initial and final assessment were compared between groups using Student's T-tests 
for normally distributed variables and the Mann-Whitney U-test for non-normally distributed variables.

In order to present an objective measure to quantify the magnitude of the treatment effect (Effect Size) we calculated the coefficients d Cohen (Cohen's d) for both the primary outcome (grip strength) and secondary outcomes in the analysis for independent samples (CGXEG).

Further, a statistical power was calculated for the primary outcome (grip strength) and 5\% significance level. The statistical power achieved was $15.6 \%$. Considering that this study was a pilot, if the observed difference between groups were to remain similar, the sample size to achieve a power of $80 \%$ is expected to be 39 patients per group.

In order to determine whether the PRWE and DASH evaluation tools are as sensitive to carpal tunnel syndrome as the BCTQ it was performed the Pearson correlation test.

\section{Results}

The sample consisted of 11 women with an average age of $54( \pm 6)$ years, of which 6 made up the CG and 5 the EG. They were withdrawn from work were $63.6 \%$. And $45.4 \%$ had completed elementary education degree. All volunteers had right dominance, and of these, 10 (90.9\%) were diagnosed with carpal tunnel syndrome in both hands, all being treated conservatively, with an average dysfunction duration of $48( \pm 30)$ months.

In the intragroup analysis, comparing the initial and final values for each variable, it can be seen that in the CG there was a decrease in the average values of sensitivity and grip strength, whereas in the EG both of these variables exhibited an increase. Results from the pinch pulp-to-pulp test were increased in both groups, most notably for EG, exhibiting an average increase of $1 \mathrm{kgf}$. Regarding functional assessments (DASH and BTCQ-EEF) and reduction in symptoms (PRWE-Pain and BTCQ-EGS), results were positive for both groups, as represented by lower values (Table 1).

The average reduction in strength and sensitivity observed in the CG group reflects the decrease in grip strength in 3 (50\%) women, while all of those from EG had increased grip strength and sensitivity. Five (83.4\%) women in the CG had decreased sensitivity, with only 1 from EG (20\%) showing decreased sensitivity.

In the intragroup analysis, we observed a higher gain in grip strength and pinch for the EG, but this gain was not statistically significant. For most variables, the best results were found observed in the EG, but without statistical significance. When analysed the effect size it observed that for objective variables (measured by means of instruments) the effect size is greater than in the variables measured by questionnaires (Table 2).

Table 1 - Mean values and standard deviations of the variables analysed and $P$ values in the intra-group analysis

\begin{tabular}{|c|c|c|c|c|c|c|c|}
\hline \multirow[t]{2}{*}{$\begin{array}{l}\text { Theoretical } \\
\text { variables }\end{array}$} & \multirow[t]{2}{*}{$\begin{array}{l}\text { Operating } \\
\text { variables }\end{array}$} & \multicolumn{2}{|c|}{$\begin{array}{l}\text { Classic therapeutic kine- } \\
\text { siotherapy group (CG) }\end{array}$} & \multirow{2}{*}{$\begin{array}{l}\text { P value (CG) } \\
\text { evaluation } \\
\text { IEV X FEV }\end{array}$} & \multicolumn{2}{|c|}{$\begin{array}{l}\text { Experimental group } \\
(E G)\end{array}$} & \multirow{2}{*}{$\begin{array}{c}\begin{array}{c}\text { P value (EG) } \\
\text { evaluation }\end{array} \\
\text { IEV X FEV }\end{array}$} \\
\hline & & IEV & FEV & & IEV & IEV & \\
\hline \multirow[t]{5}{*}{$\begin{array}{l}\text { Mechanical } \\
\text { reorganization }\end{array}$} & Sensitivity & $12.8( \pm 1.9)$ & $\begin{array}{l}10.8 \\
( \pm 2.3)\end{array}$ & $0.04^{*}$ & $10.6( \pm 5.2)$ & $11.2( \pm 3.6)$ & 0.63 \\
\hline & Grip strength & $\begin{array}{l}19.4 \\
( \pm 8.4)\end{array}$ & $\begin{array}{l}19.1 \\
( \pm 7.7)\end{array}$ & 0.53 & $20.5( \pm 4.3)$ & $22.4( \pm 3.9)$ & $0.002^{*}$ \\
\hline & $\begin{array}{l}\text { Pinch pulp-to- } \\
\text { pulp }\end{array}$ & $\begin{array}{l}2.7 \\
( \pm 1.6)\end{array}$ & $\begin{array}{l}2.9 \\
( \pm 0.8)\end{array}$ & 0.62 & $\begin{array}{l}3.3 \\
( \pm 0.8)\end{array}$ & $\begin{array}{l}4.3 \\
( \pm 1.5)\end{array}$ & 0.05 \\
\hline & BCTQ - EEF & $\begin{array}{l}3.1 \\
( \pm 0.6)\end{array}$ & $\begin{array}{l}2.6 \\
( \pm 0.8)\end{array}$ & 0.13 & $\begin{array}{l}3.4 \\
( \pm 0.3)\end{array}$ & $\begin{array}{l}3.1 \\
( \pm 0.9)\end{array}$ & 0.56 \\
\hline & DASH & $\begin{array}{l}52.4 \\
( \pm 14.1)\end{array}$ & $\begin{array}{l}42.2 \\
( \pm 14.4)\end{array}$ & 0.26 & $64.8( \pm 8.2)$ & $50.7( \pm 28.2)$ & 0.23 \\
\hline \multirow[t]{2}{*}{$\begin{array}{l}\text { Reduction of } \\
\text { symptoms }\end{array}$} & BCTQ - EGS & $\begin{array}{l}3.3 \\
( \pm 0.5)\end{array}$ & $\begin{array}{l}2.5 \\
( \pm 0.9)\end{array}$ & $0.0006^{*}$ & $\begin{array}{l}3.2 \\
( \pm 0.3)\end{array}$ & $\begin{array}{l}2.7 \\
( \pm 1.3)\end{array}$ & 0.38 \\
\hline & PRWE-Pain & $\begin{array}{l}37.3 \\
( \pm 11.2)\end{array}$ & $\begin{array}{l}32.8 \\
( \pm 10.6)\end{array}$ & 0.24 & $36.6( \pm 10.6)$ & $34.4( \pm 19.6)$ & 0.77 \\
\hline
\end{tabular}

Note: BCTQ-EGS = Boston Carpal Tunnel Questionnaire - Questionnaire - Symptom Severity Scale; PRWE-Pain = Patient Rated Wrist Evaluation - Pain; BCTQ-EEF = Boston Carpal Tunnel Questionnaire - Functional Status Scale; DASH = Disabilities of the Arm, Shoulder and Hand. IEV = Initial Evaluation; FEV = Final Evaluation; *Significant at $p>0,05$ in Student's t- test. 
Table 2 - Average values, standard deviations, confidence interval limits of the variables analysed and P values and Cohen's $d$ in the intergroup analysis

\begin{tabular}{|c|c|c|c|c|c|c|c|c|}
\hline \multirow[t]{2}{*}{$\begin{array}{l}\text { Theoretical } \\
\text { variables }\end{array}$} & \multicolumn{2}{|c|}{$\begin{array}{l}\text { Operating } \\
\text { variables }\end{array}$} & \multirow{2}{*}{$\begin{array}{c}\text { Difference } \\
\text { between } \\
\text { FEV and } \\
\text { IEV } \\
\text { Average } \\
\text { (SD) } \\
\end{array}$} & \multicolumn{2}{|c|}{ Confidence interval } & \multirow{2}{*}{$\begin{array}{l}\text { P value } \\
\text { group } \\
\text { CG X EG }\end{array}$} & \multirow[t]{2}{*}{ Cohen's d } & \multirow{2}{*}{$\begin{array}{c}\text { Effect } \\
\text { magni- } \\
\text { tude }\end{array}$} \\
\hline & & & & $\begin{array}{c}\text { Inferior } \\
\text { limit }\end{array}$ & $\begin{array}{l}\text { Upper } \\
\text { bound }\end{array}$ & & & \\
\hline \multirow[t]{5}{*}{$\begin{array}{l}\text { Mechanical } \\
\text { reorganization }\end{array}$} & Sensitivity & CG & $\begin{array}{c}-2.0 \\
( \pm 1.79)\end{array}$ & -3.88 & -0.12 & 0.08 & 1.21 & Large \\
\hline & & EG & $\begin{array}{c}0.60 \\
( \pm 2.60)\end{array}$ & -2.64 & 3.84 & & & \\
\hline & Grip strength & CG & $\begin{array}{c}-0.30 \\
( \pm 4.65)\end{array}$ & -5.18 & 4.58 & 0.36 & 0.89 & Moderate \\
\hline & & EG & $\begin{array}{c}1.90 \\
( \pm 0.65)\end{array}$ & 1.09 & 2.70 & & & \\
\hline & $\begin{array}{l}\text { Pinch pulp- } \\
\text { to-pulp }\end{array}$ & CG & $\begin{array}{c}0.23 \\
( \pm 1.27)\end{array}$ & -1.10 & 1.57 & 0.63 & 0.70 & Large \\
\hline \multirow[t]{9}{*}{$\begin{array}{l}\text { Reduction of } \\
\text { symptoms }\end{array}$} & & EG & $\begin{array}{c}0.98 \\
( \pm 0.81)\end{array}$ & -0.03 & 1.99 & & & \\
\hline & BCTQ - EEF & CG & $\begin{array}{c}-0.52 \\
( \pm 0.97)\end{array}$ & -1.54 & 0.50 & 0.75 & 0.29 & Small \\
\hline & & EG & $\begin{array}{c}-0.25 \\
( \pm 0.88)\end{array}$ & -1.35 & 0.84 & & & \\
\hline & DASH & CG & $\begin{array}{c}-10.13 \\
( \pm 19.66)\end{array}$ & -30.77 & 10.49 & 0.76 & 0.19 & Insignificant \\
\hline & & EG & $\begin{array}{c}-14.17 \\
( \pm 22.85)\end{array}$ & -42.53 & 14.20 & & & \\
\hline & BCTQ - EGS & CG & $\begin{array}{c}-0.79 \\
( \pm 0.43)\end{array}$ & -1.23 & 0.34 & 0.59 & 0.37 & Small \\
\hline & & EG & $\begin{array}{c}-0.51 \\
( \pm 1.17)\end{array}$ & -1.96 & 0.95 & & & \\
\hline & PRWE-Pain & CG & $\begin{array}{c}-4.5 \\
( \pm 6.22)\end{array}$ & -11.08 & 2.03 & 0.64 & 0.22 & Small \\
\hline & & EG & $\begin{array}{c}-2.20 \\
( \pm 16.16)\end{array}$ & -22.27 & 17.87 & & & \\
\hline
\end{tabular}

Note: BCTQ-EGS = Boston Carpal Tunnel Questionnaire - Questionnaire - Symptom Severity Scale; PRWE-Pain = Patient Rated Wrist Evaluation - Pain; BCTQ-EEF = Boston Carpal Tunnel Questionnaire - Functional Status Scale; DASH = Disabilities of the Arm, Shoulder and Hand. IEV = Initial Evaluation; FEV = Final Evaluation; Compared CGXEG, the variable difference between the initial and final grip strength, not normally distributed, and thus investigated with the Mann-Whitney U-test. For

With respect to results from the questionnaires, there was improvement in aspects related to pain and upper limb function for both groups. Questionnaires were compared in symptom (BCTQ-EGS and PRWEPain) and function modules (BCTQ-EEF and DASH), through the Pearson correlation coefficient, considering only the initial time, prior to interventions, to ensure homogeneity between the groups. For symptoms, there was a weak correlation $(R=0.22)$ between the scores from BCTQ-EGS and PRWE-Pain questionnaires. However, functionality exhibited a strong correlation $(\mathrm{R}=0.79)$, when comparing the BCTQ-EEF and DASH questionnaires.

\section{Discussion}

This study hypothesised that a physical therapy approach using a focused strategy, not only for symptoms and distal peripheral compression, but emphasising the importance of the entire nerve pathway from its origin, carried out with cervical segmental stabilization techniques and neural mobilization, would result in faster nerve recovery, minimizing functional deficits caused by disease progression.

A number of literature sources report on stretching of the flexor and extensor muscles of the wrist for individuals with CTS $(22,24)$, accentuating the 
physiological effect of increased local blood flow that promotes a decrease in the inflammatory process, with possible reduction of tension and compression of structures inside the carpal tunnel, reducing pain and paraesthesia (25). However, Ellui et al. (26), noted that the normal pressure within the carpal tunnel is approximately $2.5 \mathrm{mmHg}$ and $3.0 \mathrm{mmHg}$ for increases during flexion or full extension of the wrist, respectively, and that in patients with CTS, this pressure is normally around $90 \mathrm{mmHg}$. When the interstitial pressure exceeds normal values, the capillary blood flow is reduced below the level required to maintain axoplasmic flow, resulting in impaired nerve conduction and exacerbation of symptoms (6). Sustained stretching, besides increasing pressure within the carpal tunnel, continues to generate tension on a nerve that is in distress by trapping. As an example, specific tests for CTS involve stretching of the median nerve, such as the neural provocation of the median nerve test (10) and tests developed by Phalen (27). However, with consideration for the pathophysiological reasoning of nerve compression in the carpal tunnel, indiscriminate use of stretching for the wrist flexors and extensors is not recommended for individuals with CTS.

The significance of highlighting the nerve root, with activation of the deep neck muscles as a means of manipulating the spacing of the intervertebral foramina, was established by O'Leary et al. (28), who reported that, when the neck muscles fail to perform appropriately, the head increases its weight by $20 \%$ under the cervical vertebrae, resulting in a decrease in the spacing of the intervertebral foramina, and thus nervous clamping. Importantly, the cervical spine is characterised by a region of extreme motor function, and the superficial cervical muscles are crucial for maintaining the orientation of the head relative to the chest and your move, as deep musculature is more inherently involved in active support, such as that related to positioning of the vertebrae and maintenance of cervical angle (28). As a result, the main component of the treatment program for the experimental group was structured around stabilizing the cervical segment associated with the mobilization of the median nerve, as proposed in the Panjabi model (23).

In this study, a significant decline in sensitivity in the territory of the median nerve was observed in the CG, when comparing initial and final assessments. However, no volunteer had a considerable loss of sensation, and the lowest score in either group was three, inferring that a reduction in sensitivity was related only to preserving the ability to prevent injury. When considering the results presented for EG, we note that the exercises aimed at mobilization of the wrist, such as neural mobilization and tendon slip of the flexor muscles of the fingers, tended to improve sensitivity in the territory of the median nerve, reduce symptoms and improve function. We propose that this may be explained by an improvement in nerve conduction, achieved by increasing the nervous axoplasmic flow and decreasing compression in the carpal tunnel. Seradge, Jia, and Owens (29), surgically engaged a catheter to a blood pressure measurement transducer inside the carpal tunnel, and found that the pressure of this region decreases after one minute of active and intermittent movement of the wrist and fingers, and remains reduced for more than 15 minutes following completion of these movements. Thus, mobilization of the wrist with scheduled and guided exercises in CTS patients can result in reduced pressure in the tunnel, reduction of local oedema by improving venous return, a decrease in the contact area between the median nerve and the transverse ligament, and an improvement in blood flow and oxygenation of the neural tissue and adjacent tissues (30).

The reduction in grip strength and pinch in those with CTS may be explained by a decrease in action potentials fired by the nerve in the motor plate, responsible for muscle contraction, as a result of nerve compression process, resulting in atrophy of the thenar eminence and characteristic chronic compressive diseases $(31,32)$. The effectiveness of surgical treatment using median nerve decompression with a palmar incision is widely discussed in the literature. Some authors have studied the efficacy of surgical procedures in relation to hand strength (33). In other research, the impact of surgical decompression was examined with respects to outcomes in hand strength (34) and the return of grip strength from baseline, with positive outcomes observed three months postoperatively and substantial increases over a period of 2 years following surgery (35). However, there are no studies addressing outcomes in hand strength following physical therapy intervention in patients currently under conservative treatment for CTS. Maciel et al. (36) examined the efficacy of neural mobilization of the median nerve in 10 healthy women and identified increases in peak grip strength and muscle recruitment in the wrist flexors and fingers, following 
intervention. In the present study, we observed a significant improvement in the maximum strength of grip after 12 weeks of physical therapy intervention for the EG, whom did not undertake muscle strengthening in the treatment protocol, but instead the isometric activation of the intrinsic hand muscles, associated with mobilization of the median nerve.

When considering symptoms, there was an improvement in both groups, but the CG had a higher improvement rate than EG in outcomes drawn from the BCTQ and PRWE. As for functionality evaluated with DASH, EG had an average improvement greater than the CG, but both exhibited better functional ability in the final assessment, as compared to the initial assessment. Structured questionnaires, even if conducted strictly by the evaluator, are typically influenced by the subjectivity of the individual perception of each patient. We suggest that, in this study, those women with a higher self-esteem were more diligent with physiotherapy, and scored lower in the questionnaires at the time of final assessment, as these individuals sought to minimize the impact of the disease on their lives. Notably, it appeared that most women in the CG had this profile.

The choice of 3 questionnaires for symptomatic and functional assessment was made as a means of obtaining a broader and more thorough approach to the impact of the disease on the lives of individuals. As a specific questionnaire for CTS, the BCTQ was used as a guide to done correlations and about the values observed it is the most suitable questionnaire for the evaluation of symptoms. Given this specificity, the BCTQ is irreplaceable; other questionnaires such as the PRWE lack the relevance to substitute for BCTQ. As for analysis of the functions of the upper limbs and hands, both BCTQ and DASH questionnaires are of great value in understanding the impact of the disease on the daily activities of patients. Importantly, even if a strong or weak correlation exists, it is ideal to apply multiple questionnaires, as differing assessments resolve distinct specifics that result in a more complete assessment of the individual.

\section{Conclusion}

We conclude that the proposed protocol, focusing on neural mobilization and cervical segmental stabilization, for patients undergoing conservative treatment for CTS, exhibits better results in mechanical reorganization, reflected in increased strength, sensitivity, and improved functionality when faced to group with conventional kinesiotherapy, without the same impact on reducing symptoms. We believe that this pilot study is a first step in future research with a larger number of subjects, to elucidate the complexity of peripheral nerve, at both distal and proximal ends, and eventually a physical therapy protocol that adequately matches this complexity.

\section{References}

1. Kim HS, Joo SH, Cho HK, Kim YW. Comparison of proximal and distal cross-sectional areas of the median nerve, carpal tunnel, and nerve/tunnel index in subjects with carpal tunnel syndrome. Arch Phys Med Rehabil. 2013;94(11):2151-6.

2. Kirchhoff DC, Monducci D, Alves LP, Pereira L, Okuda FA, Takey AM, et al. Casuística e follow up de 1.639 casos de síndrome do túnel do carpo operados por técnica aberta protocolada no serviço: comparação dos nossos resultados com os obtidos por outras técnicas segundo a literatura. J Bras Neurocir. 2012;23(1):329. Portuguese.

3. Nora DB, Becker J, Ehlers JA, Gomes I. What symptoms are truly caused by median nerve compression in carpal tunnel syndrome? Clin Neurophysiol. 2005;116(2):275-83.

4. Premoselli S, Sioli P, Grossi A, Cerri C. Neutral wrist splinting in carpal tunnel syndrome: a 3-and 6-months clinical and neurophysiologic follow-up evaluation of night-only splint therapy. Eura Medicophys. 2006;42(2):121-6.

5. Upton AM, Mccomas A. The double crush in nerve-entrapment syndromes. Lancet. 1973;302(7825):359-62.

6. Thurston A. Carpal tunnel syndrome. Orthopaedics and Trauma. 2013;27(5):332-41.

7. Schmid AB, Coppieters MW. The double crush syndrome revisited - A Delphi study to reveal current expert views on mechanisms underlying dual nerve disorders. Man Ther. 2011;16(6):557-62.

8. Hebert JJ, Koppenhaver SL, Magel JS, Fritz JM. The relationship of transversus abdominis and lumbar multifidus activation and prognostic factors for clinical success with a stabilization exercise program: a cross-sectional study. Arch Phys Med Rehabil. 2010;91(1):78-85. 
9. Richardson C, Hides J, Hodges P. Fisioterapia para estabilização lombopélvica: um sistema de controle motor para tratamento e prevenção da lombalgia. 2nd ed. São Paulo: Phorte; 2011. 320 p.

10. Butler DS, Jones MA. Mobilização do sistema nervoso. Barueri (Brazil): Manole; 2003. Portuguese.

11. Shacklock M. Clinical neurodynamics: a new system of musculoskeletal treatment. Elsevier Health Sciences; 2005 [cited 2015 Jul 1]. Available from: http://tinyurl. com/jblhow7.

12. Bell-Krotoski J, Tomancik E. The repeatability of testing with Semmes-Weinstein monofilaments. J Hand Surg. 1987;12(1):155-61.

13. Rosén B, Lundborg G. A new model instrument for outcome after nerve repair. Hand Clin. 2003;19(3):463-70.

14. Blair SJ, McCormick E, Bear-Lehman J, Fess EE, Rader E. Evaluation of impairment of the upper extremity. Clin Orthop Relat Res. 1987;221:42-58.

15. Fernandes L, Bertoncello D, Pinheiro NM, Drumond LC. Correlações entre força de preensão manual e variáveis antropométricas da mão de jovens adultos. Fisioter Pesq. 2011;18(2):151-6. Portuguese.

16. Fess EE, Moran C. Clinical assessment recommendations. Indianopolis: American Society of Hand Therapists Monograph; 1981.

17. Campos CC, Manzano GM, Andrade LB, Castelo A, Nóbrega JAM. Tradução e validação do questionário de avaliação de gravidade dos sintomas e do estado funcional na síndrome do túnel do carpo. Arq Neuropsiquiatr. 2003;61(1):51-5. Portuguese.

18. Orfale AG, Araújo PMP, Ferraz MB, Natour J. Translation into Brazilian Portuguese, cultural adaptation and evaluation of the reliability of the Disabilities of the Arm, Shoulder and Hand Questionnaire. Braz J Med Biol Res. 2005;38:2.

19. Rodrigues EKS, Fonseca MCR, MacDermid JC. Brazilian version of the Patient Rated Wrist Evaluation (PRWEBR): Cross-cultural adaptation, internal consistency, test-retest reliability and construct validity. J Hand Ther. 2015;28(1):69-76.

20. MacDermid JC. Development of a scale for patient rating of wrist pain and disability. J Hand Ther. 1996;9(2):178-83.
21. Piazzini DB, Aprile I, Ferrara PE, Bertolini C, Tonali P, Maggi L, et al. A systematic review of conservative treatment of carpal tunnel syndrome. Clin Rehabil. 2007;21(4):299-314.

22. Santos CMT, Pereira CU. Reabilitação na síndrome do túnel do carpo. 2015 [cited Jul 1]. Arq Bras Neurocir. Available from: http://tinyurl.com/zrr575a.

23. Panjabi MM. The stabilizing system of the spine. Part II. Neutral zone and instability hypothesis. J Spinal Disord Tech. 1992;5(4):390-7.

24. David DR, Oliveira DAP, Oliveira RF. Atuação da fisioterapia na Síndrome do Túnel do Carpo-Estudo de caso. ConScientiae Saude. 2009;8(2):295-9. Portuguese.

25. Uhl TL, Madaleno JA. Rehabilitation concepts and supportive devices for overuse injuries of the upper extremities. Clin Sports Med. 2001;20(3):621-39.

26. Ellui VMC, Fonseca MCR, Mazzer PYN, Mazzer N, Barbieri CH. Síndromes Compressivas no Membro Superior. In: Freitas PP. Reabilitação da Mão. São Paulo: Atheneu; 2005. Portuguese.

27. Phalen GS. The carpal-tunnel syndrome. J Bone Joint Surg. 1966;48(2):211-28.

28. O'Leary S, Falla D, Elliott JM, Jull G. Muscle dysfunction in cervical spine pain: implications for assessment and management. J Orthop Sports Phys Ther. 2009;39(5):324-33.

29. Seradge $H$, Jia YC, Owens W. In vivo measurement of carpal tunnel pressure in the functioning hand. J Hand Surg Am. 1995;20(5):855-9.

30. Rozmaryn LM, Dovelle S, Rothman ER, Gorman K, Olvey KM, Bartko JJ. Nerve and tendon gliding exercises and the conservative management of carpal tunnel syndrome. J Hand Ther. 1998;11(3):171-9.

31. Gould III JA. Fisioterapia na ortopedia e na medicina do esporte. São Paulo: Manole; 1993. Portuguese.

32. Pardini Jr AG. Traumatismos da mão. 3rd ed. Rio de Janeiro: Medsi; 2000. Portuguese.

33. Silva JB, Fontes Neto P, Foucher G, Fridman M. Estudo prospectivo randomizado da força pós-operatória após diferentes técnicas de liberação do túnel do carpo. Rev Bras Ortop. 1996;34(4):355. 
34. Leonel L, Santos MAB, Meirelles LM, Gomes JB, Santos FF, Albertoni WM, et al. Reavaliação a longo prazo do tratamento cirúrgico da síndrome do túnel do carpo por incisão palmar e utilização do instrumento de Paine $^{\circledR}$. Acta Ortop Bras. 2005;13(5):225.

35. Katz JN, Fossel KK, Simmons BP, Swartz RA, Fossel $\mathrm{AH}$, Koris MJ. Symptoms, functional status, and neuromuscular impairment following carpal tunnel release. J Hand Surg Am. 1995;20(4):549-55.

36. Maciel TS, Cruz VWC, Jorge FS, Arêas FZS, Ribeiro Junior SMS. Efeitos da mobilização neural sobre a força, resistência e recrutamento muscular dos flexores de punho. Ter Man. 2012;10(50):411-6. Portuguese.

Received in 07/07/2015

Recebido em 07/07/2015

Approved in 11/03/2015

Aprovado em 03/11/2015 
